\title{
Dr. Leon S. Dure, III (1931-2014)
}

\author{
Joe L. Key ${ }^{1}$ Andrzej B. Legocki ${ }^{2}$ Jacques H. Weil ${ }^{3}$
}

Published online: 1 April 2015

(C) Springer Science+Business Media Dordrecht 2015

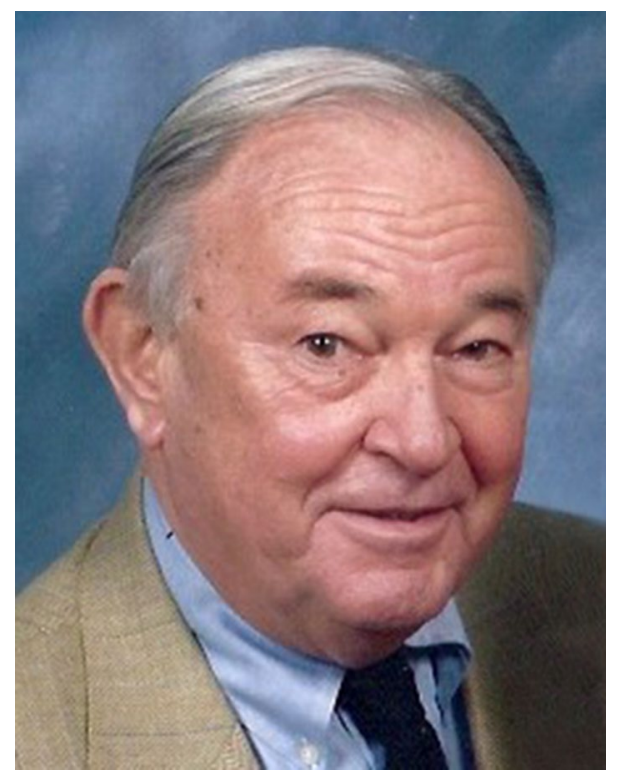

Dr. Leon S. Dure III passed away on May 11, 2014. He was Franklin Professor of Biochemistry at the time of his retirement from the University of Georgia (UGA), Athens, Georgia, where he spent his entire faculty career from 1960 to 2003.

Born in January 1931 in Macon, Georgia, Leon grew up at his family home in East Belmont Farm, Kenswick, Virginia. He graduated from the University of Virginia

Jacques H. Weil

jhweil@unistra.fr

1 University of Georgia, Athens, GA, USA

2 Institute of Bioorganic Chemistry, Polish Academy of Sciences, Poznan, Poland

3 Institut de Botanique, Strasbourg, France

with a bachelor's degree in philosophy, and then served as a Marine Corps officer in the mountains of Korea. After returning home and leaving formal duty in the Marines (because of Leon's loyalty and love for the Marine Corps as well as his patriotism, he remained an active reserve Officer, reaching the rank of Colonel before retiring from the Marine Reserves), Leon returned to the University of Virginia where he received an M. S. degree in plant embryology. He then continued his graduate education at the University of Texas where he received his Ph.D. in plant physiology. After this, Leon joined the developing faculty of biochemistry of the UGA in 1960 as a postdoctoral researcher working on bioluminescence-a pioneering step as he was in fact the first postdoctoral researcher at the UGA! He continued on the faculty of biochemistry and retired in 2003 as Franklin Professor of Biochemistry after a distinguished research career. Leon was also greatly respected as a masterful teacher, which the Franklin professorship validated as one of the best.

In the mid-1960s, Dr. Dure developed his independent research laboratory where he focused on the molecular bases of seed germination. During this early period, one of the important findings was discovery and characterization of long-lived messenger or mRNA that coded for specialized proteins in germinating cotton seed. This was one of the earliest reports on the long-term stability of at least some eukaryotic mRNAs. Leon's group did one of the most thorough and excellent studies at the time on PolyA + and Poly A-mRNAs in a plant system. Dr. Dure's research continued to focus on many aspects of cotton seed embryogenesis and germination, including additional work on the seed mRNAs and studies on cotton seed storage proteins from general characterization of their complexity and abundance to biosynthetic pathways. The role of abscisic acid in these processes represents another major group of contributions. 
Leon devoted an immense amount of time and energy in the early 1980s in trying to convince the leaders and their colleagues in plant molecular biology of the need to establish an International Society of Plant Molecular Biology-this developing from his own insight, which was both enhanced and solidified by three exceedingly successful ad hoc meetings held in 1976 (organized by Jacques Weil in Strasbourg, France), 1979 (organized by Chris Leaver in Edinburgh, UK) and 1982 (organized by Orio Ciferri in Porto Portese, Italy). The result of this effort was realized in 1984 when the ISPMB became a reality. Dure was recognized as the founder with his election as president. He became globally recognized in the burgeoning community of plant molecular biologists, and was selected by an advisory group to organize the first International Congress of the ISPMB, held in Savannah, Georgia in 1985. Organizing this congress was a mammoth undertaking and an even greater success by any measure. The interest in and need for the ISPMB were validated with almost 1800 scientists being pre-registered weeks before the congress convened! This overall initiative and its formal continuation for 20 years has been exceedingly important in bringing together the growing community of plant molecular biologists. Ad hoc meetings continue even after the dissolution of the ISPMB.

To Dr. Leon S. Dure III, scientist, professor, philosopher, historian, friend and colleague, and to many of his friends in and beyond science the Consummate Southern Gentleman, a job well done. 